Original Article

\title{
FORMULATION AND IN VITRO EVALUATION OF SALBUTAMOL SULPHATE AND THEOPHYLLINE EXTENDED-RELEASE TABLETS USING MODIFIED POLYMERS
}

\author{
NAVEEN GOYAL ${ }^{a}$, ANIL KUMAR ${ }^{b^{*}}$

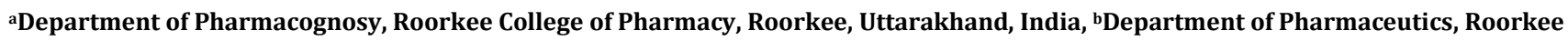 \\ College of Pharmacy, Roorkee, Uttarakhand, India \\ Email: anildost78@gmail.com
}

Received: 09 May 2018 Revised and Accepted: 07 Jul 2018

\begin{abstract}
Objective: The main objective of this research work was to design, prepare and evaluate extended release (ER) tablets of anti-asthmatic drugs (salbutamol sulphate and theophylline) by direct compression method using diverse ratios of hydroxypropyl methylcellulose (HPMC K100M) and ethyl cellulose (EC) along with some other excipients.

Methods: Extended-release matrix tablets of salbutamol sulphate and theophylline were successfully fabricated by direct compression method and coded the formulations as F1 to F7 depending on the ratios of modified polymers. The core tablets composed of hydrophilic polymers of various ratios that allow the discharge of drugs at a controlled rate after coming in contact with the aqueous medium. The designed tablets were subjected to various assessment parameters i.e. friability test, hardness test, drug content consistency and In vitro dissolution tests.

Results: Prepared formulations were subjected to various assessment parameters and the findings obtained were within the prescribed limit. To perform the in vitro drug dissolution tests of fabricated tablets, the calibration plots of pure drugs using various solvents i.e. $0.1 \mathrm{~N} \mathrm{HCl}$, phosphate buffer ( $\mathrm{pH}$ 6.8) and distilled water were plotted. Dosage forms F1-F7 containing ethyl cellulose and HPMC K100M in various concentration demonstrates the prolonged medications discharge for up to $8 \mathrm{~h}$, among these formulations, F6 shows $95.32 \pm 0.24 \%$ for salbutamol sulphate and $94.19 \pm 0.39 \%$ for theophylline release at the end of $8 \mathrm{~h}$. This finding reveals that a particular window of concentrations of ethylcellulose and HPMC K100M was capable of providing prolonged drugs discharge.
\end{abstract}

Conclusion: The results obtained in this research work clearly showed a promising potential of extended-release tablets containing a specific ratio of HPMC $\mathrm{K} 100 \mathrm{M}$ and ethylcellulose as a release rate controlling polymers for effective treatment of asthma and chronic obstructive pulmonary diseases (COPD).

Keywords: Salbutamol sulphate, Theophylline, HPMC K100M, Ethylcellulose and Extended-release tablets

(C) 2018 The Authors. Published by Innovare Academic Sciences Pvt Ltd. This is an open access article under the CC BY license (http://creativecommons.org/licenses/by/4.0/) DOI: http://dx.doi.org/10.22159/ijpps.2018v10i8.27865

\section{INTRODUCTION}

Tablets have been the most preferred oral dosage form for the patients suffering from chronic diseases like bronchial asthma, chronic bronchitis and chronic obstructive pulmonary diseases (COPD) because of low-cost therapy and ease of administration [1, 2]. The traditional tablets provide only a single and transient release of the drug. The pharmaceutical effect has only seen for the time duration in which the concentration of the drug remains within the therapeutic range that can be best achieved with ER tablets [3]. The significance of administering single-dose extended-release tablet that has discharged over an extended timeframe instead of multiple doses becomes the area of interest for the formulation designing scientists in the Pharmaceutical industry [4]. The oral prolonged discharge dosage form has been prepared for those medications that are comfortably absorbed from the gastrointestinal tract (GIT), have a short half-life and eliminated quickly from the bloodstream [5].

The terms sustained action, sustained discharge, controlled discharge, timed release, prolonged action, depot, extended action and repository formulations have been used to represent the novel drug delivery system (NDDS) and formulated to get an extended therapeutic effect by continuously discharging drug over a prolonged time period after administration of a single dose [6]. There might be several other reasons also for the attractiveness of these dosage forms viz. provides enhanced bioavailability of medication, lessening in the recurrence of administration to extend the timeframe of effective blood levels, reduces the fluctuation of the peak-trough level and adverse effects and possibly enhances the particular distribution of the medication [7].

Salbutamol sulphate and theophylline drugs show the synergistic effect in terms of producing prolonged bronchodilation for the treatment of reversible bronchospasm and COPD [8]. The short halflife of salbutamol sulphate and theophylline (4 to $6 \mathrm{hr}$ ) drugs increases the frequency of drug administration as an immediate release dosage form but makes them the best candidates for the design of extended-release tablets [9]. The present study aims to formulate, fabricate and evaluate the once-daily dose of extendedrelease matrix tablets using hydrophilic polymers, such as HPMC $\mathrm{K} 100 \mathrm{M}$ and ethylcellulose in different ratios.

\section{MATERIALS AND METHODS}

\section{Materials}

The drugs salbutamol sulphate and theophylline were obtained as a gift sample from Elegant Drugs Pvt. Ltd., Karnataka and Koves India Ltd. Chennai. Polymers HPMC K100M and ethylcellulose were purchased from Evonik Degussa and Titan Biotech Ltd., Bhiwadi, Rajasthan. All used reagents and chemicals were procured from commercial stores and also of a good analytical grade.

\section{Methodology}

\section{Establishment of the calibration data}

In order to conduct the in vitro drug dissolution studies, the calibration tables containing data of pure drugs using different solvents viz. $0.1 \mathrm{~N}$ $\mathrm{HCl}$, phosphate buffer ( $\mathrm{pH} \mathrm{6.8)} \mathrm{and} \mathrm{distilled} \mathrm{water} \mathrm{were} \mathrm{constructed.}$ Calibration data has been used to find out the concentration of unknown sample taken from the dissolution media during dissolution studies at an equal interval of time. For this, $10 \mathrm{mg}$ of salbutamol sulphate was accurately weighed and transferred into a $10 \mathrm{ml}$ volumetric flask containing approximately $5 \mathrm{ml}$ of $0.1 \mathrm{~N} \mathrm{HCl}$. Flask was then gently shaken to dissolve its contents and volume was finally made up to $10 \mathrm{ml}$ using the same solvent and was labeled as stock 
solution "A". $1 \mathrm{ml}$ of this solution was pipetted out in another volumetric flask and volume was made up to $10 \mathrm{ml}$ with $0.1 \mathrm{~N} \mathrm{HCl}$ in order to obtain the resulting solution of $100 \mu \mathrm{g} / \mathrm{ml}$, it was then labeled as stock solution "B". Finally by using stock solution "B", solutions of various concentrations such as $2,4,6,8,10,12 \mu \mathrm{g} / \mathrm{ml}$ were prepared. $0.1 \mathrm{~N} \mathrm{HCl}$ was taken as blank and absorbance of different dilutions were taken at $277 \mathrm{~nm}$ (nanometer) similarly, standard plots of pure salbutamol sulphate were also constructed at the same $\lambda_{\max }$ using phosphate buffer and distilled water.
Similarly, the same procedure was followed for the drug theophylline to prepare the dilutions of different concentrations i.e. $2,4,6,8,10,12 \mu \mathrm{g} / \mathrm{ml}$ with all three solvents $(0.1 \mathrm{~N} \mathrm{HCl}$, Phosphate buffer and distilled water). The absorbance of all dilutions for theophylline was taken at $271 \mathrm{~nm} \lambda_{\max }[10,11]$.

Table 1 and 2 enlisted the standard curve data of salbutamol sulphate and theophylline in $0.1 \mathrm{~N} \mathrm{HCl}$, phosphate buffer $(\mathrm{pH}$ 6.8) and distilled water respectively.

Table 1: Standard plot data of salbutamol Sulphate in $0.1 \mathrm{~N} \mathrm{HCl}$

\begin{tabular}{|c|c|c|c|c|}
\hline \multirow[t]{2}{*}{ S. No. } & \multirow{2}{*}{ Conc. $(\mu \mathrm{g} / \mathrm{ml})$} & \multicolumn{3}{|c|}{ Average absorbance } \\
\hline & & $0.1 \mathrm{~N} \mathrm{HCl}$ & Phosphate buffer (pH 6.8) & Distilled water \\
\hline 1 & 2 & 0.1213 & 0.1128 & 0.1191 \\
\hline 2 & 4 & 0.2423 & 0.2374 & 0.2312 \\
\hline 3 & 6 & 0.3689 & 0.3496 & 0.3742 \\
\hline 4 & 8 & 0.5065 & 0.4302 & 0.5012 \\
\hline 5 & 10 & 0.6258 & 0.5380 & 0.6243 \\
\hline 6 & 12 & 0.7371 & 0.6529 & 0.7491 \\
\hline
\end{tabular}

Table 2: Standard plot data of theophylline

\begin{tabular}{lllll}
\hline S. No. & Conc. $(\boldsymbol{\mu g} / \mathbf{m l})$ & \multicolumn{3}{l}{ Average absorbance } \\
\cline { 3 - 4 } & & $\mathbf{0 . 1 N}$ HCl & Phosphate buffer (pH 6.8) & Distilled water \\
\hline 1 & 2 & 0.1104 & 0.1121 & 0.1072 \\
2 & 4 & 0.2107 & 0.2197 & 0.2088 \\
3 & 6 & 0.2989 & 0.3221 & 0.3316 \\
4 & 8 & 0.3952 & 0.4296 & 0.4526 \\
5 & 10 & 0.5274 & 0.5285 & 0.5979 \\
6 & 12 & 0.6196 & 0.6313 & 0.6882 \\
\hline
\end{tabular}

\section{Preparation of extended-release tablets}

ER tablets of salbutamol sulphate and theophylline (F1-F7) were fabricated by developing the formulae utilizing variable concentrations of two polymers viz. HPMC K100M and ethylcellulose as shown in table 3. The concentrations of salbutamol sulphate and theophylline were kept consistent for all groups of formulations.
Salbutamol sulphate, theophylline and various excipients were weighed precisely apart from magnesium stearate and talc, after that blended in a mortar with a pestle for 10-15 min. After the blending of medications with excipients, the required quantity of talc and magnesium stearate was included and additionally blending was done for 4-5 min. The gross weight of every tablet was kept at $250 \mathrm{mg}[12,13]$.

Table 3: Formulations of ER tablets of salbutamol sulphate and theophylline

\begin{tabular}{|c|c|c|c|c|c|c|c|}
\hline \multirow[t]{2}{*}{ Ingredients (mg) } & \multicolumn{7}{|c|}{ Formulation code } \\
\hline & F1 & F2 & F3 & F4 & F5 & F6 & F7 \\
\hline Salbutamol sulphate & 4 & 4 & 4 & 4 & 4 & 4 & 4 \\
\hline Theophylline & 100 & 100 & 100 & 100 & 100 & 100 & 100 \\
\hline HPMC K100M & 40 & 50 & 60 & - & - & 40 & 50 \\
\hline Ethylcellulose & - & - & - & 60 & 75 & 60 & 75 \\
\hline Lactose & 100 & 90 & 80 & 80 & 65 & 40 & 15 \\
\hline Magnesium stearate & 2 & 2 & 2 & 2 & 2 & 2 & 2 \\
\hline Talc & 4 & 4 & 4 & 4 & 4 & 4 & 4 \\
\hline Total weight & 250 & 250 & 250 & 250 & 250 & 250 & 250 \\
\hline
\end{tabular}

\section{Evaluation of extended-release tablets}

Prepared formulations (F1-F7) were assessed for different parameters like hardness, friability, content uniformity and in vitro dissolution test.

\section{Friability}

To assess the capability of the tablet to withstand wear and tear in packing, handling and transporting, friability test was done by Roche Friabilator. Pick randomly twenty tablets and weight ( $\left.W_{0}\right)$ and were subjected to the joined impact of wearing down and shock by utilizing a plastic chamber $(25 \mathrm{rpm})$ dropping the tablets at a separation of 6 inches with each revolution, operated for 100 revolutions. Each tablet was dusted and reweighed (W) after completion of 100 revolutions. The \% friability was calculated using this formula [14].

$$
\text { Friability }(\%)=\frac{W 0-W}{W O} \times 100 \ldots \text { eq } 1
$$

\section{Tablet hardness}

This represents the pressure which is required to crush the tablet. Monsanto hardness tester was used to determine the hardness of prepared tablets. The average hardness and standard deviation were determined and the hardness of $4 \mathrm{~kg}$ is considered to be least for a satisfactory tablet $[15,16]$.

\section{Uniformity of drug content}

Assay of ER tablets of salbutamol sulphate and theophylline was performed in distilled water to find out the number of drugs present in one tablet. For this 2 tablets were weighed and powdered in a glass mortar and $250 \mathrm{mg}$ of the powder equivalent to $4 \mathrm{mg}$ of salbutamol sulphate and $100 \mathrm{mg}$ of theophylline was placed in two separate $100 \mathrm{ml}$ volumetric flasks and dissolved in $100 \mathrm{ml}$ water. The resulting solution was filtered and absorbance was recorded at $\lambda_{\max } 277 \mathrm{~nm}$ for salbutamol sulphate and $\lambda_{\max } 271 \mathrm{~nm}$ for theophylline using UV visible spectrophotometer. The concentration 
of medications in milligram per millilitre was calculated from standard calibration plots of drugs $[17,18]$.

\section{In vitro drug release studies}

In vitro release of salbutamol sulphate and theophylline from ER tablets was obtained separately by using USP type II (Paddle Type) dissolution apparatus in $900 \mathrm{ml}$ of phosphate buffer of $\mathrm{pH}$ 6.8 at the constant temperature of $37^{\circ} \pm 0.5^{\circ} \mathrm{C}$ at $50 \mathrm{rpm}$. Aliquots $(5 \mathrm{ml})$ of the solutions were taken out from the dissolution apparatus at various time intervals and replaced with fresh dissolution medium to maintain the sink condition. Samples were filtered and the absorbance of these solutions was observed by using a double beam ultra-violet spectrophotometer at $277 \mathrm{~nm}$ and $271 \mathrm{~nm}$ for salbutamol sulphate and theophylline respectively against fresh phosphate buffer solution as the blank $[19,20 \%]$.

\section{RESULTS AND DISCUSSION RESULTS}

Observations of evaluation of various parameters are depicted in table 4,5 and 6 . Table 5 and table 6 represents the \% cumulative drug release versus time profile of in vitro dissolution studies for both drugs (salbutamol sulphate and theophylline).

Table 4: Evaluation of extended release matrix tablets

\begin{tabular}{llllll}
\hline Code & $\begin{array}{l}\text { Hardness } \\
\left(\mathbf{K g} / \mathbf{c m}^{2} \mathbf{)}\right.\end{array}$ & $\begin{array}{l}\text { Friability } \\
\mathbf{( \% )}\end{array}$ & $\begin{array}{l}\text { Weight (mg) } \\
\text { mean } \pm \text { SD }\end{array}$ & $\begin{array}{l}\text { Drug content (\%) } \\
\text { Salbutamol sulphate }\end{array}$ & $\begin{array}{l}\text { Thickness (mm) } \\
\text { mean } \pm \text { SD }\end{array}$ \\
\hline F1 & $5.5 \pm 0.40$ & $0.49 \pm 0.068$ & $249.6 \pm 3.32$ & $95.57 \pm 0.560$ & $4.15 \pm 0.11$ \\
F2 & $5.8 \pm 0.35$ & $0.46 \pm 0.016$ & $250.4 \pm 2.25$ & $99.67 \pm 1.06$ & $4.27 \pm 0.10$ \\
F3 & $5.1 \pm 0.21$ & $0.30 \pm 0.073$ & $248.7 \pm 2.31$ & $97.51 \pm 0.66$ & $95.42 \pm 0.42$ \\
F4 & $5.3 \pm 0.24$ & $0.32 \pm 0.065$ & $248.7 \pm 2.31$ & $98.49 \pm 1.34$ & $99.65 \pm 0.71$ \\
F5 & $5.4 \pm 0.21$ & $0.41 \pm 0.064$ & $249.5 \pm 2.31$ & $97.41 \pm 0.87$ & $99.18 \pm 0.38$ \\
F6 & $5.7 \pm 0.11$ & $0.48 \pm 0.091$ & $252.3 \pm 2.68$ & $101.39 \pm 0.42$ & $97.48 \pm 0.65$ \\
F7 & $5.3 \pm 0.14$ & $0.41 \pm 0.072$ & $248.5 \pm 2.49$ & $102.23 \pm 0.82$ & $4.28 \pm 0.11$ \\
\hline
\end{tabular}

All values are mean $\pm S D$ of three determinations

Table 5: In vitro drug release profile of salbutamol sulphate

\begin{tabular}{|c|c|c|c|c|c|c|c|}
\hline Time (h) & F1 & F2 & F3 & F4 & F5 & F6 & F7 \\
\hline 0 & 0 & 0 & 0 & 0 & 0 & 0 & 0 \\
\hline 1 & $32.50 \pm 0.33$ & $26.49 \pm 0.83$ & $18.20 \pm 0.53$ & $09.20 \pm 0.53$ & $08.56 \pm 0.29$ & $14.22 \pm 0.80$ & $11.87 \pm 0.66$ \\
\hline 2 & $46.41 \pm 0.34$ & $36.50 \pm 0.62$ & $25.69 \pm 0.40$ & $13.69 \pm 0.40$ & $13.31 \pm 0.58$ & $28.56 \pm 0.84$ & $15.21 \pm 0.61$ \\
\hline 3 & $57.49 \pm 0.62$ & $44.24 \pm 0.77$ & $39.38 \pm 0.82$ & $21.38 \pm 0.82$ & $20.86 \pm 0.22$ & $42.01 \pm 0.60$ & $22.31 \pm 0.24$ \\
\hline 4 & $72.65 \pm 0.13$ & $59.50 \pm 0.53$ & $51.42 \pm 0.19$ & $27.42 \pm 0.19$ & $27.77 \pm 0.49$ & $57.59 \pm 0.62$ & $28.29 \pm 0.47$ \\
\hline 5 & $99.03 \pm 0.56$ & $71.34 \pm 0.73$ & $65.29 \pm 0.07$ & $36.29 \pm 0.07$ & $37.54 \pm 0.91$ & $75.52 \pm 0.73$ & $38.05 \pm 0.84$ \\
\hline 6 & $99.17 \pm 0.63$ & $81.29 \pm 0.80$ & $76.18 \pm 0.73$ & $49.18 \pm 0.73$ & $45.38 \pm 0.37$ & $84.09 \pm 0.96$ & $52.73 \pm 0.09$ \\
\hline 7 & $99.12 \pm 0.78$ & $99.08 \pm 0.44$ & $85.51 \pm 0.78$ & $60.51 \pm 0.78$ & $50.11 \pm 0.47$ & $92.44 \pm 0.38$ & $61.24 \pm 0.67$ \\
\hline 8 & $99.34 \pm 0.45$ & $99.85 \pm 0.61$ & $89.44 \pm 0.91$ & $71.44 \pm 0.91$ & $60.32 \pm 0.27$ & $95.32 \pm 0.24$ & $78.06 \pm 0.42$ \\
\hline 12 & $99.42 \pm 0.35$ & $99.59 \pm 0.57$ & $91.19 \pm 0.65$ & $71.19 \pm 0.65$ & $71.22 \pm 0.31$ & $96.35 \pm 0.54$ & $84.16 \pm 0.65$ \\
\hline 24 & $99.48 \pm 0.18$ & $99.55 \pm 0.51$ & $92.67 \pm 0.87$ & $73.67 \pm 0.87$ & $71.62 \pm 0.27$ & $97.99 \pm 0.55$ & $86.01 \pm 0.69$ \\
\hline
\end{tabular}

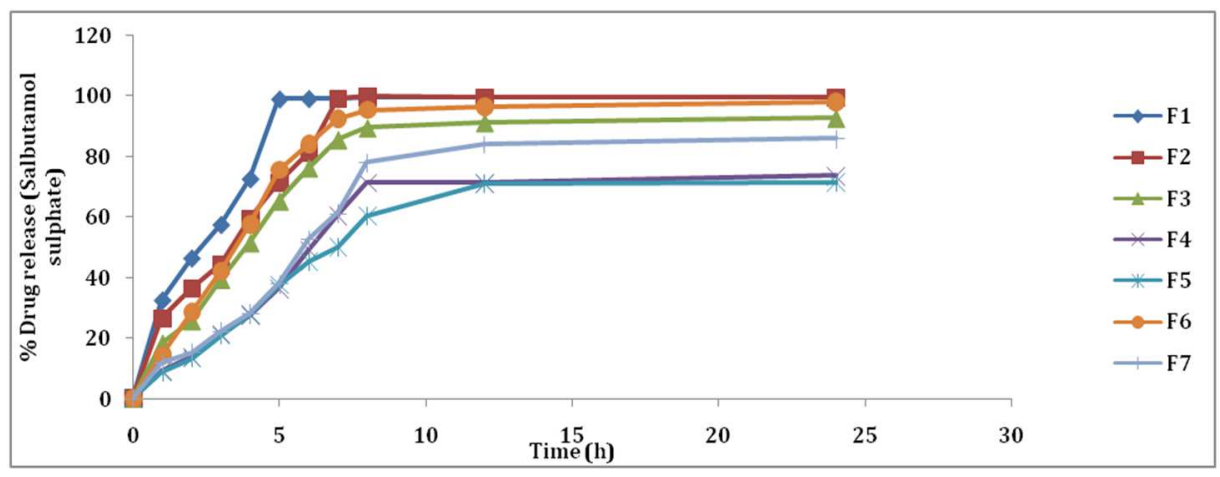

Fig. 1: Graphical representation of dissolution profile of salbutamol sulphate (F1-F7)

Table 6: In vitro drug release profile of theophylline

\begin{tabular}{|c|c|c|c|c|c|c|c|}
\hline Time(h) & F1 & F2 & F3 & F4 & F5 & F6 & F7 \\
\hline 0 & 0 & 0 & 0 & 0 & 0 & 0 & 0 \\
\hline 1 & $28.06 \pm 0.39$ & $21.80 \pm 0.22$ & $17.66 \pm 0.61$ & $09.11 \pm 0.53$ & $07.55 \pm 0.63$ & $12.49 \pm 0.78$ & $10.16 \pm 0.18$ \\
\hline 2 & $43.73 \pm 0.63$ & $32.08 \pm 0.21$ & $23.05 \pm 0.47$ & $14.62 \pm 0.73$ & $13.09 \pm 0.77$ & $27.03 \pm 0.22$ & $14.19 \pm 0.45$ \\
\hline 3 & $54.67 \pm 0.45$ & $39.11 \pm 0.42$ & $37.66 \pm 0.29$ & $23.25 \pm 0.54$ & $19.36 \pm 0.52$ & $39.66 \pm 0.03$ & $20.42 \pm 0.62$ \\
\hline 4 & $68.91 \pm 0.32$ & $57.38 \pm 0.76$ & $48.01 \pm 0.35$ & $27.33 \pm 0.61$ & $27.56 \pm 0.35$ & $55.84 \pm 0.18$ & $26.17 \pm 0.11$ \\
\hline 5 & $96.55 \pm 0.43$ & $69.65 \pm 0.88$ & $64.97 \pm 0.46$ & $35.78 \pm 0.23$ & $35.45 \pm 0.21$ & $73.15 \pm 0.36$ & $37.72 \pm 0.86$ \\
\hline 6 & $98.84 \pm 0.56$ & $77.03 \pm 0.37$ & $74.38 \pm 0.75$ & $45.63 \pm 0.72$ & $45.76 \pm 0.55$ & $81.36 \pm 0.82$ & $52.36 \pm 0.28$ \\
\hline 7 & $98.34 \pm 0.67$ & $96.48 \pm 0.62$ & $82.86 \pm 0.44$ & $49.69 \pm 0.57$ & $51.88 \pm 0.56$ & $90.47 \pm 0.42$ & $59.15 \pm 0.10$ \\
\hline 8 & $98.11 \pm 0.31$ & $97.64 \pm 0.55$ & $86.48 \pm 0.39$ & $58.66 \pm 0.11$ & $59.44 \pm 0.34$ & $94.19 \pm 0.39$ & $73.04 \pm 0.62$ \\
\hline 12 & $98.12 \pm 0.81$ & $97.36 \pm 0.58$ & $89.66 \pm 0.21$ & $69.02 \pm 0.26$ & $68.21 \pm 0.36$ & $94.68 \pm 0.43$ & $80.73 \pm 0.51$ \\
\hline 24 & $98.36 \pm 0.44$ & $97.63 \pm 0.70$ & $89.54 \pm 0.11$ & $77.19 \pm 0.27$ & $75.48 \pm 0.39$ & $94.36 \pm 0.12$ & $81.33 \pm 0.14$ \\
\hline
\end{tabular}




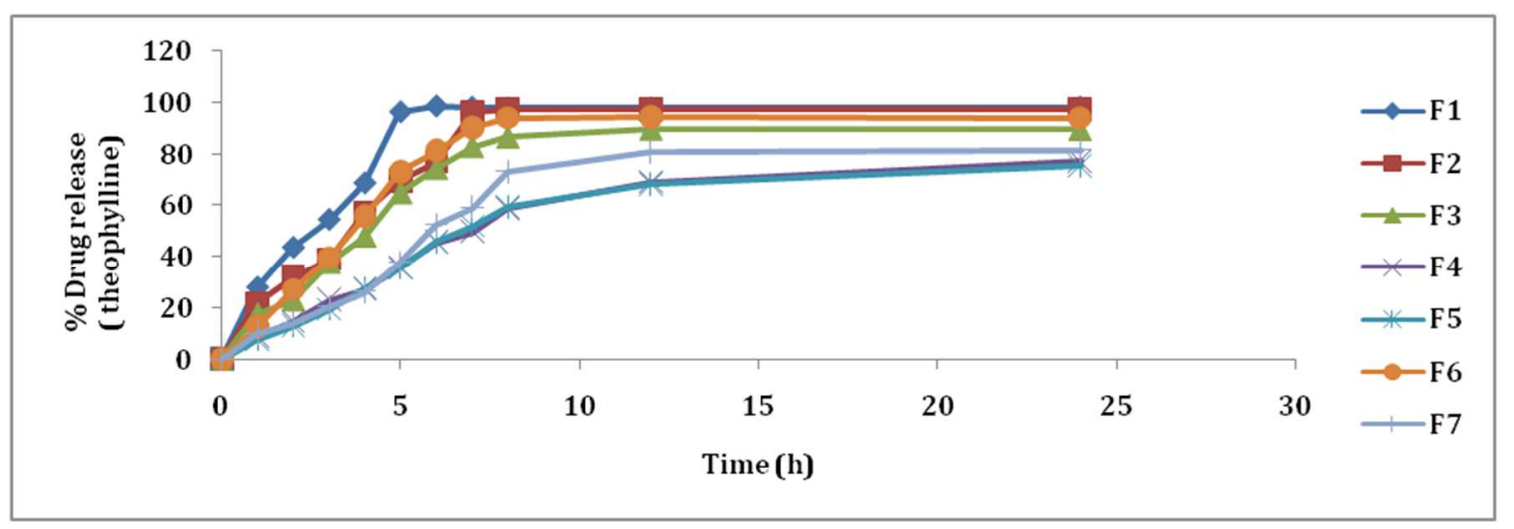

Fig. 2: Graphical representation of dissolution profile of theophylline (F1-F7)

\section{DISCUSSION}

Prepared formulations were subjected to various assessment parameters and the findings obtained were within the limits which are depicted in table 4 . The hardness of all the tablets was within a range of $5.1 \pm 0.12$ to $5.8 \pm 0.32 \mathrm{~kg} / \mathrm{cm}^{2}$. Weight loss of all tablets in friability test lay in a range of $0.30 \pm 0.098$ to $0.49 \pm 0.057 \%$. The $\%$ drug content for various tablet formulations was in the range from $95.57 \pm 0.560$ to $102.23 \pm 0.82 \%$ for salbutamol sulphate and $95.88 \pm 0.36 \%$ to $100.11 \pm 0.31 \%$ for theophylline. The F- 6 containing HPMC K100M and ethylcellulose (2:3 ratios) was selected as the optimum formulation on the basis of the results of in vitro dissolution tests. It is seen that at the end of $8 \mathrm{hr}, 95.32 \pm 0.24 \%$ salbutamol sulphate and $94.19 \pm 0.39 \%$ theophylline were released from the formulation.

\section{CONCLUSION}

The extended-release tablets of salbutamol sulphate and theophylline using specific ratio (2:3) of HPMC K100M and ethylcellulose can be successfully fabricated by direct compression method. Concentrations and ratios of used polymers i.e. HPMC $\mathrm{K} 100 \mathrm{M}$ and ethylcellulose can affect the release of the drugs from the dosage form. Among the prepared batches of ER tablets based on performance with respect to friability, hardness, uniformity of drug content and in vitro \% cumulative drug release studies, F6 delivers the best results. The formulation F6 discharge required loading dose concentration and maximum percentage cumulative drugs release over a period of $8 \mathrm{~h}$ which is $95.32 \pm 0.24 \%$ for salbutamol sulphate and $94.19 \pm 0.39 \%$ for theophylline.

It can be concluded from the observations that formulation F- 6 has achieved the objectives of extended-release formulations i.e. patient convenience by reducing dosing frequency, reduction in toxicity, enhanced effectiveness of the drug by localization at the site of action and cost-effectiveness as an ER once daily dosage form.

\section{ACKNOWLEDGEMENT}

The authors of the manuscript would like to acknowledge Elegant Drugs Pvt. Ltd., Karnataka and Koves India Ltd., Chennai for providing gift samples of salbutamol sulphate and theophylline. The authors would also thankful to principal and management of Roorkee College of Pharmacy, Roorkee, Uttarakhand for allowing us to avail the facilities of experimentations.

\section{AUTHORS CONTRIBUTIONS}

Experimental design, guidance, supervision and review work for the research was done by $\mathrm{Dr}$ Naveen Goyal, Principal (Director), Roorkee College of Pharmacy, Roorkee, Uttarakhand. Experimental work, interpretation of result and writing of this manuscript was done by Anil Kumar, Assistant Professor, Roorkee College of Pharmacy, Roorkee, Uttarakhand. Both authors read and approve the final manuscript.

\section{CONFLICTS OF INTERESTS}

All authors have none to declare

\section{REFERENCES}

1. Chauhan MJ, Patel SA. A concise review of sustained drug delivery system and its opportunities. Am J Pharm Tech Res 2012;2:227-32.

2. Arafat M. Approaches to achieve an oral controlled release drug delivery system using polymers: a recent review. Int J Pharm Pharm Sci 2015;7:16-21.

3. Pachuau L, Sarkar S, Mazumdar B. Formulation and evaluation of matrix microspheres for simultaneous delivery of salbutamol sulphate and theophylline. Trop J Pharm Res 2008; 7:995-1002.

4. Panda S, Kumari CHS, Puniya G. Formulation and evaluation of compression coating floating tablets of carvedilol phosphate once daily dose. Int J Pharm Pharm Sci 2018;10:82-9.

5. Nallam M, Venugopalaiah P, Prakash KG, Goninath M, Naresh P. Formulation and evaluation of salbutamol sulphate extendedrelease tablets. Int J Curr Pharm Res 2015;3:1030-5.

6. Mallikarjun V, Babu VR, Ravi P, Narender, Rajkamala B. Formulation and evaluation of bilayered sustained release matrix tablets of salbutamol sulphate and theophylline. Inventi Rapid; Pharm Tech 2015;1:1-7.

7. Rao SK, Babu BR, Nagamounika V, Gopikapriyanka K, Sarswathi $P$. Formulation and optimization of sustained release matrix tablet of salbutamol sulphate. J Pharmacokinet Pharmacodyn 2015;1:1-8.

8. Parashar T, Soniya, Singh V, Singh G, Tyagi S, Patel C, et al. Novel oral sustained release technology: a concise review. Int J Res Dev Pharm Life Sci 2013;2:262-9.

9. Ummadi S, Shravani B, Rao NGR, Reddy MS, Nayak BS Overview of controlled release dosage form. Int J Pharm Sci 2013;3:258-69.

10. Sharma PP, Sharma S, Khokra SL, Sahu RK, Jangde R, Singh J, et al. Formulation, development and evaluation of sustained release matrix tablets containing salbutamol sulphate. Pharmacologyonline 2011;1197-203.

11. Rajalaxmi G, Balachandar R, Damodharan N. Formulation and evaluation of theophylline sustained release matrix tablet. Der Pharm Lett 2011;3:1-7.

12. Kamalakkannan V, Venkartraman P, Sivaorakash R, Kumar RS, Kumaran KSGA. Formulation and evaluation of controlled release matrix tablet of salbutamol sulphate using various cellulose polymers. J Chem Pharm Res 2015;7:42-54.

13. Mote PB, Rawat PK, Singh SK, Zadbuke NS, Salunke AA, Rajendra VB, et al. Formulation and evaluation of sustained release matrix tablets of an anti-asthmatic agent using various polymers. J Drug Delivery Ther 2013;3:88-92.

14. Sujana K, Venu S, Sravani K, Iswarya P. Simultaneous estimation of salbutamol and Theophylline in bulk drugs and marketed formulation using simultaneous equation method. Int J Pharm Tech Res 2016;9:274-82.

15. Murthy PNVN, Shafiullah D, Murthy D. Formulation, development and evaluation of sustained release matrix tablets of guaiphenesin and salbutamol sulphate. Pharm Lett 2011;3:325-34. 
16. Sekharan TR, Palanichamy S, Shanmuganathan $S$, Karthikeyan A, Senthilkumar SR, Thirupathi AT, et al. Formulation and evaluation of theophylline controlled release matrix tablets using xanthan gum. Pharm Lett 2009;1:93-101.

17. Madhavi C, Ramesh Y, Deepathi A, Gnana PK, Gobinath M, Rao SK, et al. Formulation and evaluation of sustained release matrix tablets of cefadroxil by using direct compression method. Am J Pharm Tech Res 2015;5:294-306.

18. Ramya SA, Latha K. Formulation and evaluation of zolpidem tartrate layered tablets by melt granulation technique for treatment of insomnia. Asian J Pharm Clin Res 2018:11:13947.

19. Ain S, Kumar B, Pathak K. Development and characterization of controlled release famotidine matrix tablets containing complexes. Int J Appl Pharm 2017:9:38-46.

20. Srinivasa RB, Vjayaratana J. Formulation and evaluation of floating matrix tablets of levofloxacin and hemihydrates using hydroxymethyl propyl cellulose $\mathrm{K} 4 \mathrm{M}$ to treat Helicobacter pylori infection. Asian J Pharm Clin Res 2018;11:148-51. 